

\title{
Acerca da aplicabilidade do conceito de experiência religiosa no estudo dos mistérios helenísticos
}

\author{
Thales Moreira Maia Silva \\ Doutorando em Ciência da Religião pela UFJF. Bacharel em História \\ e Especialista em Antropologia pela UFMG. O presente trabalho foi \\ realizado com apoio da Coordenação de Aperfeiçoamento de Pessoal \\ de Nível Superior - Brasil (CAPES) - Código de Financiamento 001. \\ E-mail: thalesmms@gmail.com.
}

Resumo: O uso de categorias permite a estudiosos realizar distinções, organizar seu material e classifica-lo de acordo com os critérios dos padrões utilizados. Entretanto, muitas vezes, tais parâmetros correspondem mais aos esquemas organizacionais atuais do que às próprias categorias antigas, mesmo quando aparentam vir diretamente do passado. A partir do exemplo das "religiões de mistério", a alegação de que uma suposta "experiência religiosa", isolada de seu contexto político, seria a base das ideias e condutas religiosas greco-romanas parece ser um posicionamento mais fundamentado em vieses (essencialistas) modernos do que nas evidências históricas.

Palavras-chave: Categorização; mistérios; experiência

On the applicability of the concept of religious experience to the study of the hellenistic mysteries

\begin{abstract}
The use of categories allow scholars to make distinctions, organize their material, and classify it according to the definitional criteria of the categories used. However, sometimes, these criteria correspond more to present organizational schemata than to ancient people's own, even when the categories used appear to come directly from the past. From the example of the Greco-Roman mystery religions, it would seem that the claim that some kind of religious experience, isolated from its political context, was the basis for ancient religious practices, ideas and institutions seems to be grounded more in modern (essentialist) bias than in historical evidence.
\end{abstract}

Keywords: Categorization; mysteries; experience. 
O significado de um texto não é algo natural ou auto-evidente, aguardando as cuidadosas descrições acadêmicas de seus intérpretes. Na realidade, sua acepção está sujeita às nossas técnicas e interesses disciplinares e, portanto, é criada e recriada a cada leitura, com cada ato de interpretação, por meio da aplicação de mecanismos hermenêuticos como, por exemplo, o anacronismo. Enquanto uma dinâmica de identificação, a projeção de pressupostos atuais sobre o passado favorece, portanto, a autenticação de interesses contemporâneos ou das abstrações dos selfs individuais; pois na medida em que esses anacronismos são vistos como transcendendo o tempo e o espaço (isto é, na medida em que assumimos que o sujeito moderno e racional é parte integrante de um, suposto, estado natural da vivência humana), eles autorizam não apenas nossa linguagem acadêmica e vocabulário técnico, mas as situações e suposições modernas que os conduzem e se beneficiam de seu uso.

No entanto, nossas práticas de identificação não se limitam ao uso de anacronismos; esses, efetivamente, são apenas uma dentre as várias técnicas utilizadas para se dar sentido ao passado de modo a (intencionalmente ou não) beneficiar o presente. Tais benefícios também decorrem da maneira como classificamos e, por conseguinte, organizamos e estruturamos nossa compreensão do mundo e de seus diferentes elementos - incluindo a Antiguidade. $\mathrm{O}$ uso de categorias permite aos estudiosos do passado realizar distinções, organizar seu material e classifica-lo de acordo com os critérios de definição dos padrões utilizados. Entretanto, muitas vezes, tais parâmetros correspondem mais aos esquemas organizacionais atuais do que às próprias categorias dos antigos, mesmo quando os padrões de categorização utilizados aparentam vir diretamente do passado. De fato, o sucesso das categorias utilizadas na descrição, organização e entendimento do mundo antigo está no aparente aspecto atemporal de seus significados.

Contudo, tal significado está nos olhos dos observadores, dos agentes que trabalham internamente às estruturas (dos leitores usando uma gramática, sintaxe e um vocabulário que lhes foram ensinados) daqueles que fazem distinções e usam taxonomias para trazer ordem ao seu mundo. Pois damos sentido ao nosso contexto de acordo com nossas próprias posições. Logo, não apenas nossas pronúncias, mas também nossas classificações são contingentes, estratégicas e relativas ao mundo no qual habitamos, a um tempo e local específicos. De forma semelhante às regras e categorias que um determinado ator social segue e usa ao conceber seu contexto - as quais são, conforme o exposto pelo historiador das religiões J. Z. 
Smith (acerca da categoria "religião") ${ }^{1}$, de sua própria criação ${ }^{2}$ - as categorias que os estudiosos empregam na leitura dos sinais que interpretam regularmente (num texto antigo, por exemplo) também podem ser indicadoras da ação de atores sociais, fazendo sentido de seus próprios mundos ao encontrarem, alhures, expressões para as distinções com as quais já estão intimamente familiarizados. ${ }^{3}$

Com efeito, em nenhum recorte dos Estudos Clássicos as implicações dos processos de categorização são mais evidentes do que na forma como os escritores modernos tentaram entender um fenômeno que parece ter sido amplamente difundido pelo mundo greco-romano. De acordo com os estudiosos da Antiguidade, junto com o que é concebido como uma "religião oficial" das cidades-estados, havia também os chamados "cultos de mistério", ou, ainda, as denominadas "associações privadas" ou "associações voluntárias", dedicadas à adoração de uma divindade específica. Essas instituições antigas exigiam que seus membros se submetessem a processos custosos de iniciação e acredita-se que a maioria delas era aberta a indivíduos que, em contrapartida, eram marginalizados pela cultura dominante de seu tempo (parece-nos, por exemplo, que mulheres, crianças, estrangeiros e até mesmo escravos podiam delas participar), ou seja, pessoas com acesso limitado àquilo que, por sua vez, é modernamente caracterizado como a "religião oficial" da cidade-estado. Como parte de seus rituais de iniciação, esses cultos são entendidos como tendo exigido o sigilo de seus membros, uma expressão que na língua grega antiga tinha seu análogo na palavra $\mu v \varepsilon \imath v$ (a qual significa "fechar"), da qual derivamos o termo moderno "mistério". De fato, é fundamentando-se nesse vocábulo que os estudiosos atuais se referem a esses grupos como "cultos de mistério", em distinção à noção dos cultos públicos de uma "religião da polis".

De modo geral, tais instituições são consideradas pelos estudiosos do mundo antigo como tendo composto uma escolha facultativa, paralela à participação prevista ou obrigatória nas práticas ritualizadas da religião oficial da cidade-estado (razão pela qual alguns autores as designam como, conforme o já mencionado, “associações voluntárias”). Consequentemente, não se tratavam de alternativas adversárias, já que esses (intitulados) "cultos opcionais" concerniam, particularmente, à promessa de uma bem-aventurada vida após a morte e/ou, até

\footnotetext{
${ }^{1}$ SMITH, Jonathan Z. Imagining Religion: From Babylon to Jonestown. Chicago: University of Chicago Press, 1982, p. XI.

${ }^{2}$ É necessário ressaltar o caráter plural dessas regras e categorias, pois não se tratam de "invenções individuais", mas, pelo contrário, construtos coletivos os quais são transmitidos e revisados pelos indivíduos de acordo com parâmetros socialmente previstos.

${ }^{3}$ TOUNA, Vaia. Fabrications of the Greek Past: Religion, Tradition, and the Making of Modern Identities. Leiden e Boston: BRILL, 2017, p. 22-49.
} 
mesmo, de um benefício mundano aos seus integrantes. ${ }^{4}$ Por conseguinte, os membros iniciados nessa forma privada e voluntária de culto a um deus ou deusa são comumente considerados pelos estudiosos da antiguidade como tendo possuído um relacionamento mais íntimo e pessoal com a divindade à qual estavam associados. ${ }^{5}$ Adicionalmente (e curiosamente), embora a literatura grega antiga esteja repleta de termos utilizados na descrição desses grupos - tais como $\mu v \sigma \tau \dot{\eta} \rho \imath \alpha$ ou óp $\gamma \imath \alpha$ - o interesse neles pelos acadêmicos modernos que investigam suas origens e tentam explicar sua função original resultou no desenvolvimento de uma variedade de novas composições. Em sua aplicação, cada categorização tenta, à sua maneira, agrupar um conjunto de atividades unicamente relacionadas, a fim de classificá-las como iguais e, então, explicar seu significado. Dessa forma, classicistas chegaram a termos gerais como (conforme o anteriormente exposto) "religiões de mistério" e "cultos de mistério", assim como "associações religiosas" privadas e voluntárias ou até mesmo "agremiações". Notavelmente, o que é comum entre todas essas categorias é a suposição (por autores modernos) de que o fenômeno ao qual se referem ilustra uma mudança crescente, tanto na autocompreensão dos antigos gregos quanto nas interpretações atuais, partindo de uma concepção dos indivíduos como cidadãos (com responsabilidades perante um Estado) para uma compreensão pessoal ou particular dos selfs

\footnotetext{
${ }^{4}$ Conforme, por exemplo, o descrito na obra conhecida como Metamorfoses ou $O$ asno de ouro (meados do século II d.C.), de autoria do escritor e filósofo romano Lúcio Apuleio, na qual a personagem principal é iniciada no culto em honra à deusa Isis sob a promessa de não apenas uma melhor "vida após a morte", mas também de benefícios para sua "vida terrena" (Apuleius, Metamorphoses, VI).

${ }^{5}$ Entre os cultos de mistério mais conhecidos estão aqueles de Elêusis, em Atenas, mas, logicamente, esses não eram os únicos. Por exemplo, os mistérios ocorridos na ilha de Samotrácia eram célebres em todo o mundo grego, ainda que, atualmente, pouco se saiba a respeito dos deuses com os quais estavam associados. Também de grande relevância eram os mistérios dionisíacos, associados a Dionísio (mais tarde reverenciado como Baco), o culto a Mitra e, logicamente, os célebres mistérios de Isis. Curiosamente, de acordo com tal classificação, possuímos cinco (denominados) "grandes mistérios" no mundo antigo, da mesma forma como, atualmente, dispomos de cinco religiões tradicionais ou "grandes religiões globais" (cristianismo, judaísmo, islamismo, budismo e hinduísmo). Trata-se, provavelmente, de uma indicação de como os estudiosos (ou, pelo menos, uma primeira geração de estudiosos) projetaram sob o passado suas próprias classificações e distinções, não apenas como forma de dar sentido à Antiguidade, mas na tentativa de produzir comparações familiares que os ajudassem a compreender seu próprio contexto. Todavia, o famoso classicista Fritz Graf enfatiza que as instituições batizadas pelos acadêmicos de "mistérios menores" (em uma comparação com os cinco "grandes mistérios" supracitados) possuíam, igualmente, uma importância impar no mundo antigo - criticando os pesquisadores que limitam suas análises apenas aos cultos mais famosos. De fato, apesar de, atualmente, esses serem alguns dos mais conhecidos mistérios greco-romanos, haviam inúmeros outros agrupamentos (como os $\underline{\theta i \alpha \sigma o l}$, os $\underline{\varepsilon} \rho \alpha v o l$, e os $\delta \rho \gamma \varepsilon \tilde{\omega} v \varepsilon \varsigma$ ), todos com as mesmas características - ou seja, instituições abertas a grupos sociais marginalizados pelo contexto cultural mais amplo no qual se encontravam (talvez com a exceção do culto de Mitra, que, até onde sabemos, era composto, primariamente, por soldados). Congruentemente, todos esses eram marcados pela presença de rituais de iniciação, do sigilo entre seus participantes e prometiam aos iniciados uma melhor vida, tanto terrena quanto após a morte (GRAF, Fritz. Lesser mysteries - Not less mysterious. In: COSMOPOULOUS, M. B. (Org.). Greek Mysteries: The Archaeology and Ritual of Ancient Greek Secret Cults. Londres e Nova York: Routledge, 2002, p. 241-262).
} 
individuais (como sendo distintos do Estado). O próprio uso de termos como "privado" ou "voluntário" torna evidente que, para muitos daqueles que estudam esse tipo de material, essa mudança é creditada como tendo ocorrido na própria Antiguidade. ${ }^{6}$ Deste modo - segundo o conjecturado por esses autores - as origens daquilo que pode ser concebido como o "indivíduo moderno" podem ser vistas como contemporâneas à existência dessas antigas instituições.

Ainda, uma suposta dimensão essencialmente religiosa desses cultos de mistério também é proeminente - ou, ao menos, é enfatizada - em todas as modernas categorias acadêmicas utilizadas em sua descrição e explicação, embora muitos estudiosos hoje concordem que o termo "religião", em si, é uma invenção moderna. Em síntese, tem-se advertido para que o vocábulo "religião", caso seja utilizado em referência à Antiguidade, seja empregado de maneira cautelosa e qualificada. ${ }^{7}$ Afinal, no mundo antigo, aquilo que hoje destacamos de todas as outras instituições sociais como "religião" não era tratado como algo distinto e, portanto, aqueles itens que hoje reconhecemos como religiosos (como as crenças sistematicamente relacionadas aos deuses, os rituais e os mitos) eram, muito provavelmente, parte integrante do complexo e amplo contexto social da polis. Com efeito, não há palavra ou conceito equivalente na literatura greco-romana antiga que se adeque ao entendimento moderno do termo "religião"8 - até mesmo o vocábulo latino religio, do qual ele se origina, possuía, na Antiguidade, um significado muito distinto. ${ }^{9}$

Com esta crítica em mente, como podemos, então, dar sentido aos estudiosos modernos que concebem aquilo que os antigos denominavam $\mu v \sigma \tau \eta \dot{\rho} \imath \alpha$ como um ambiente social e politicamente distinto, no qual um determinado fenômeno, interpretado como acessível apenas ao nível individual e hoje conhecido como "experiência religiosa", teria acontecido? Pois, atualmente, os cultos de mistério são (a despeito de várias críticas) frequentemente explicados em termos de uma suposta experiência pessoal a qual eles

\footnotetext{
${ }^{6}$ Cf. GREEN, Peter. From Alexander to Actium: The Hellenistic Age. Londres: Thames and Hudson, 1990, p. 587-589.

${ }^{7}$ NONGBRI, Brent. Before Religion: A History of a Modern Concept. New Haven e Londres: Yale University Press, 2013, p. 153.

${ }^{8}$ Cf. MCCUTCHEON, Russell T. Studying Religion: An Introduction. Londres: Equinox, 2007.

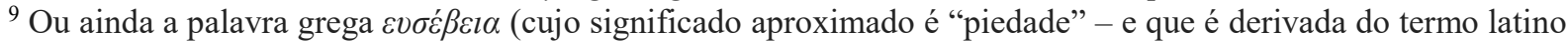
posterior pietas) - freqüentemente usada como um equivalente à palavra "religião" se referia, mais especificamente, às relações e comportamentos apropriados, tanto entre quanto em meio a humanos e deuses, ou seja, naquilo que se tangia ao reconhecimento do lugar dos indivíduos e, portanto, como se comportar adequadamente em uma variedade de situações (Idem, The Discipline of Religion: Structure, Meaning, Rhetoric. Londres: Routledge, 2003, p. 17-18).
} 
permitiam, alimentavam ou proporcionavam, algo à parte da vida pública antiga. ${ }^{10}$ Tratava-se de um ambiente (segundo aquilo reivindicado por muitos autores) onde os indivíduos ignorados pelas debilitadas instituições estatais procuravam encontrar uma conexão mais íntima com o (suposto) “divino".

Contudo, antes de entrarmos em maiores detalhes, consideremos primeiro o contexto histórico e historiográfico de um desses (assim chamados) "cultos de mistério", mais especificamente, aqueles compreendidos em Elêusis, um dos mais célebres mistérios do mundo grego antigo, assim como um dos mais prestigiosos festivais dentre aqueles organizados pela cidade de Atenas. ${ }^{11}$ Os mistérios de Elêusis eram realizados anualmente,

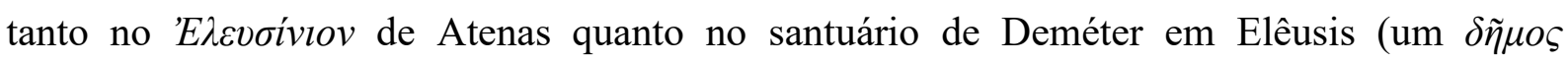
próximo a Atenas e que foi conquistado por ela em algum momento do século VI a.C.) ${ }^{12}$, estando associados com duas deidades agrícolas: Deméter e sua filha, Perséfone, também denominada Kó $\eta$. De acordo com o Hino Homérico a Deméter - um texto solene escrito, muito provavelmente, entre os séculos VII e VI a.C. - Perséfone teria sido abduzida por Hades, o deus do submundo, e Deméter, transtornada com a perda de sua filha, teria causado uma terrível seca enquanto perambulava em sua busca. ${ }^{13}$ Durante tal perambulação, ela adentrou o palácio de Celeu, rei de Elêusis, procurando por abrigo. Lá, Deméter ensinou a um dos filhos do monarca, Triptólemo, os segredos da agricultura e, em troca, ordenou que um santuário fosse erguido em sua honra:

Venham! Que um grande templo, com um grande altar em sua base, seja construído por todo o $\delta \tilde{\eta} \mu o \varsigma$. Aos pés da cidade e seus íngremes muros,

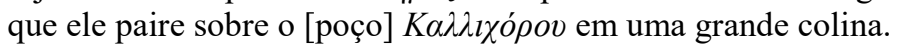

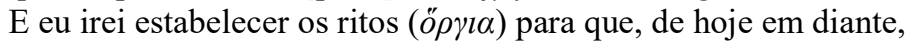
ao realizarem devidamente tais rituais, o meu espírito (vóov) seja propiciado. ${ }^{14}$

\footnotetext{
${ }^{10}$ TOUNA, Fabrications of the Greek Past, p. 37-44.

11 LARSON, Jennifer. Ancient Greek Cults: A Guide. Londres e Nova York: Routledge, 2007, p. 73-76; MARTIN, Luther H. Hellenistic Religions: An Introduction. Nova York e Oxford: Oxford University Press, 1987 , p. $60-72$.

12 Embora a tese de que Elêusis nunca tenha sido uma cidade independente (mesmo em sua origem) seja, frequentemente, mencionada em debates acadêmicos contemporâneos (SOURVINOU-INWOOD, Cristiane. Festival and mysteries: Aspects of the Eleusinian cult. In: COSMOPOULOS. Greek Mysteries, p. 26).

${ }^{13}$ Cf. FOLEY, Helene P. (Org.).The Homeric Hymn to Demeter: Translation, Commentary, and Interpretive Essays. Princeton: Princeton University Press, 1993.

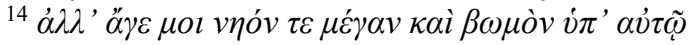

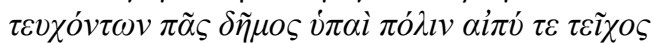

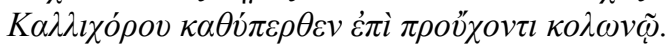

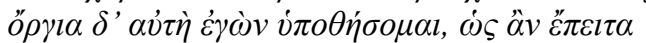

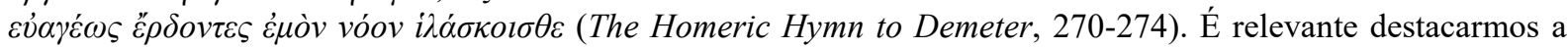
facilidade com a qual certas palavras gregas foram traduzidas sob as mais diversas formas, ao longo do histórico de recepção dos Hinos Homéricos. Por exemplo, através de termos latinos posteriormente desenvolvidos (e de suas implicações), adotados por estudiosos modernos, os vocábulos óp $\gamma l \alpha$ e vóov, por vezes, foram tratados como sinônimos de "ritos sagrados"/“ritos religiosos", "alma"/“espírito", etc. (TOUNA, Fabrications of the
} 
Eventualmente, Zeus interveio e permitiu que Perséfone passasse alguns meses de cada ano com sua mãe, enquanto o restante seria consumado na companhia de Hades. E, em termos gerais, esse enredo compõe o cerne da história fundacional dos mistérios de Elêusis.

Uma quantidade substancial de fontes antigas ${ }^{15}$ aponta para $\mathrm{o}$ fato de que as festividades em honra a Deméter e sua filha, conhecidas na época como $\tau \alpha \mu v \sigma \tau \eta ́ \rho ı$ (e atualmente como "os mistérios"), duravam vários dias. ${ }^{16}$ Inicialmente, arautos eram enviados a toda uma diversidade de cidades gregas para anunciar um armistício, o que permitia que os interessados em participar no festival, tanto como iniciados quanto como espectadores, viajassem para Atenas em segurança. ${ }^{17}$ As festividades se iniciavam com uma procissão que partia do santuário de Elêusis rumo ao seu correspondente ateniense, o 'E $\lambda \varepsilon v \sigma i ́ v i o v$ da cidade,

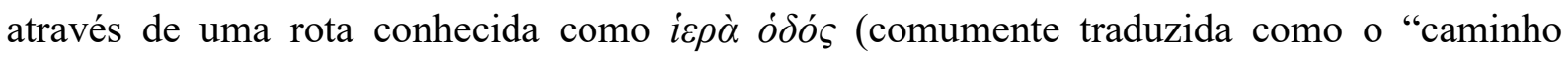

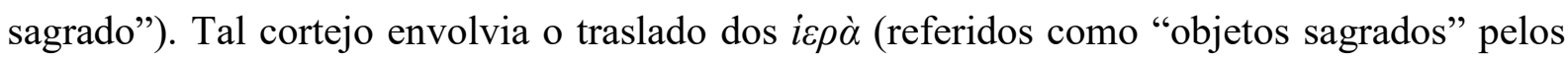
estudiosos modernos). Uma vez em Atenas, uma série de preparações eram realizadas, todas elas supervisionadas pelo $\beta \alpha \sigma l \lambda \varepsilon v ́ \varsigma$ (o “ $\alpha \rho \chi \omega v$ rei”) - o qual era designado pela cidade - e tais preparativos incluíam formalidades tais como as oferendas e sacrifícios realizados pelos vários funcionários da polis e aquelas efetuadas pelos indivíduos que desejassem a iniciação nos mistérios. ${ }^{18}$ Digno de nota, já na época no tirano Pisístrato (século VI a.C.), praticamente todos podiam ser iniciados, incluindo mulheres, crianças e, até mesmo, escravos (desde que falassem o grego e não fossem culpados de homicídio). Naquilo que se seguia, duas procissões voltavam de Atenas para Elêusis, uma composta pelos sacerdotes carregando os

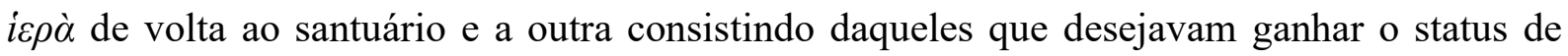
$\mu v ́ \sigma \tau \eta \varsigma$ ou $\varepsilon \pi \delta ́ \pi \tau \eta \varsigma$ (respectivamente, o título dos participantes que seriam iniciados pela primeira vez e daqueles que haviam se submetido à iniciação no ano anterior). Quando as festividades se encerravam, o $\beta \alpha \sigma l \lambda \varepsilon v$ s, o qual havia supervisionado a totalidade do festival,

Greek Past, X-XII). Aqui, o vínculo entre o termo antigo e sua tradução moderna, com todas as suas implicações (ou a falta desse vínculo), é um fator pertinente para a tese central do presente artigo.

15 Entretanto, é importante destacar que a maior parte de nosso conhecimento atual acerca dos mistérios, em termos gerais, e dos mistérios de Elêusis, em particular, advém da tendenciosa perspectiva dos primeiros apologistas cristãos, mais notavelmente dos escritos de Clemente de Alexandria, o qual foi o primeiro a mencionar os "grandes" e os "pequenos" mistérios (Clement of Alexandria, The Stromata, or Miscellanies, V.XI.70.7-V.XI.71.1; Exhortation to the Heathen, II, 13-20P), Hipólito de Roma (Hippolytus, Refutation of All Heresies, V.8.40), Tertuliano (Tertullian, Ad Nationes, II.VII; The Chaplet, or De Corona, XV.4) e Astério de Amaseia (Asterius Amasenus Episcopus, Encomium in Sanctos Martyres, 10.9.1).

${ }^{16}$ Havia também uma iniciação preliminar, a qual ocorria nos (assim chamados) "mistérios menores".

${ }^{17}$ CLINTON, Kevin. Stages of initiation in the Eleusinian and Samothracian mysteries. In: COSMOPOULOS. Greek Mysteries, p. 50-78.

18 ROBERTSON, Noel D. The two processions to Eleusis and the program of the mysteries. The American Journal of Philology, v. 119, n. 4, 1998, p. 547-575. 
retornava ao 'EAEvoíviov, em Atenas, para informar um relatório oficial às autoridades públicas. ${ }^{19}$ Notavelmente, não sabemos (ao certo) que tipo de rituais ocorriam dentro do santuário em Elêusis para que um iniciado se tornasse um $\mu v ́ \sigma \tau \eta \varsigma$, mas os estudiosos modernos frequentemente mencionam o envolvimento de três elementos: as $\delta \rho \omega ́ \mu \varepsilon v \alpha$, as $\delta \varepsilon \iota \kappa v v ́ \mu \varepsilon v \alpha$ e as $\lambda \varepsilon \gamma o ́ \mu \varepsilon v \alpha$ (ou seja, as "coisas feitas", as "coisas expostas" e as "coisas ditas").

Apesar de, atualmente, ser muito comum se referir aos vários elementos dos ritos eleusinos por meio desses três termos, tal distinção é deveras moderna. O historiador das religiões Luther H. Martin, convenientemente, observa que "[essas] categorias, no entanto, assim como as categorias modernas de mito, ritual e símbolo, são, meramente, convenções acadêmicas que fornecem um quadro teórico conveniente, embora não-técnico, para a argumentação acerca dos mistérios". ${ }^{20}$ De fato, tais termos são encontrados em algumas fontes antigas, mas apenas na mera descrição de que os indivíduos viam, ouviam e faziam algumas coisas durante os festivais, algo que é completamente trivial, uma vez que qualquer tipo de evento envolveria esses atos. ${ }^{21}$ Aquilo que, aqui, nos interessa é a forma como os estudiosos contemporâneos ${ }^{22}$, de certo modo, conceberam esse emprego moderno e técnico do vocabulário grego antigo. ${ }^{23}$ Pois, ao mencionarem apenas a formulação atual desses elementos (ao invés das fontes originais), os quais alegam compor os ritos eleusinos, muitos classicistas modernos não apenas acabam por naturalizar os conceitos gregos de sua própria concepção, como se, auto-evidentemente, eles existissem no passado, mas, também, privilegiam o uso moderno da língua grega antiga como sendo a forma mais legítima de expressão daquilo que, originalmente, ocorria nos mistérios. ${ }^{24}$ Trata-se de um intrigante caso de alternância linguística que promove, ainda mais, a legitimidade de sua escrita contemporânea.

Partindo de tais pressupostos, muitos dentre esses estudiosos explicam o surgimento e

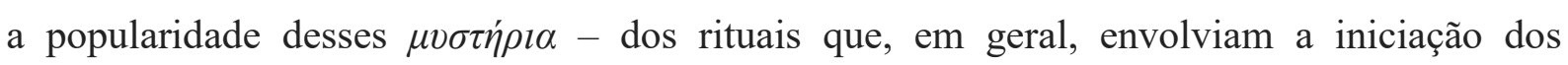
membros nos cultos de mistério - sob a rubrica de que eram "experiências": variações de um

\footnotetext{
${ }^{19}$ CLINTON, Stages of initiation in the Eleusinian and Samothracian mysteries, p. 51.

${ }^{20}$ MARTIN, Hellenistic Religions, p. 61.

${ }^{21} \mathrm{O}$ biógrafo e ensaísta grego Plutarco, por exemplo, escreve a respeito daquilo que os adoradores, nos mistérios

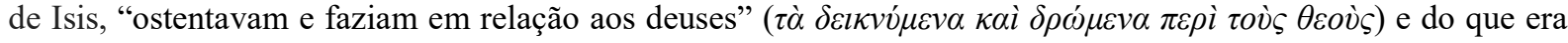

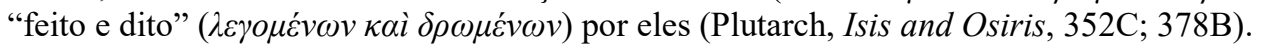

${ }^{22}$ Fundamentando-se na tradição acadêmica francesa dos princípios do século XX, a qual decidiu pelo uso formulaico e não, meramente, descritivo de tais termos, por meio do próprio vocabulário grego antigo, ao invés da língua francesa, na designação de certos comportamentos deveras mundanos, executados pelo povo helênico (em outras palavras, ver, ouvir e fazer).

${ }^{23}$ MARTIN, Luther, H. Studies in Hellenistic Religions. Eugene: Cascade Books, 2018, p. 182-187.

${ }^{24}$ Cf. BOWDEN, Hugh. Mystery Cults of the Ancient World. Princeton e Oxford: Princeton University Press, 2010, p. 38.
} 
presumido "estado interno de disposições", entendidas como centrais ou, até mesmo, a essência daquilo que chamamos de "religião". ${ }^{25}$ Essa noção de uma "experiência transformadora" que (embora quase nunca, realmente, contextualizada e explicada), supostamente, era sentida de forma profunda pelos iniciados, em conjunto com a temática da busca individual pela salvação pessoal, compõe um traço proeminente das agendas de pesquisa de muitos classicistas empenhados na análise das fontes antigas em sua tentativa de entender os sinais do mundo helenístico e suas religiões de mistério. ${ }^{26}$

Entretanto, em tais produções acadêmicas, a falta de atenção ao contexto de seu objeto de pesquisa é particularmente relevante se (de acordo com o recém-exposto) considerarmos que um dos mais conhecidos cultos de mistério da antiguidade, os mistérios de Elêusis, eram um dos principais festivais públicos de Atenas, tendo inclusive o $\beta \alpha \sigma i \lambda \varepsilon v ́ \varsigma$ - que era nomeado pela própria cidade - como seu supervisor. Por exemplo, em sua obra Sobre os Mistérios, o orador ateniense Andócides escreve:

Foi quando retornávamos de Elêusis, depois do informe já ter sido registrado contra mim. ${ }^{27} \mathrm{O} \beta \alpha \sigma l \lambda \varepsilon \dot{\varsigma} \varsigma$ apresentou-se perante aos $\pi \rho v \tau \dot{v} v \varepsilon l \varsigma$ para fornecer o rotineiro relato oficial de tudo o que havia ocorrido durante a execução das cerimônias ( $\tau \varepsilon \lambda \varepsilon \tau \eta \dot{v} v)$ naquela cidade. Os $\pi \rho v \tau \dot{\alpha} v \varepsilon l \varsigma$ disseram que eles iriam leva-lo para a presença do Conselho $\left(\beta o v \lambda \eta^{\prime}\right)$ e pediram para que ele notificasse ambos, eu e

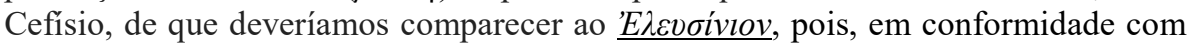
uma lei de Sólon - a qual estabelecia que uma sessão deveria ser realizada no

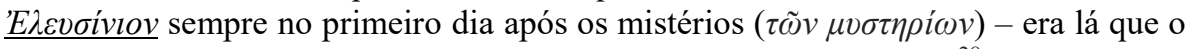
Conselho haveria de se reunir. Ambos comparecemos pontualmente. ${ }^{28}$

No entanto, para muitos autores modernos, esse papel sócio-político óbvio, assim como todo o contexto do festival, não parece implicar nada de relevante acerca da função e ofício desses mistérios na vida pública da cidade. Pelo contrário, apesar daquilo que pode ser caracterizado como seu notório contexto político, os festivais de Elêusis são uniformemente

\footnotetext{
${ }^{25}$ Cf. NILSSON, Martin. Greek Folk Religion. Nova York: Harper, 1961, p. 64; BURKERT, Walter. Ancient Mystery Cults. Cambridge e Londres: Harvard University Press, 1987, p. 3-11; p. 30-53.

${ }^{26}$ SHARF, Robert H. Experience. In: TAYLOR, Mark C. (Org.). Critical Terms for Religious Studies. Chicago: University of Chicago Press, 1998, p. 94-116; FITZGERALD, Timothy. Experience. In: BRAUN, W., MCCUTCHEON, R. T. (Orgs.). Guide to the Study of Religion. Londres e Nova York: Cassell, 2000, p. 125139; Cf. MARTIN, Craig, MCCUTCHEON, Russell T. (Org.). Religious Experience: A reader. Sheffield: Equinox, 2012.

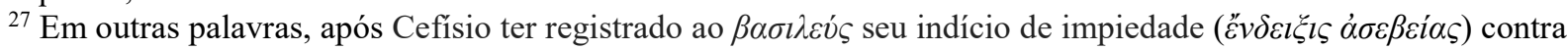
Andócides. De acordo com uma antiga lei da cidade de Atenas, o $\beta \alpha \sigma l \lambda \varepsilon v$ $\varsigma$ deveria, então, se apresentar perante o $\beta o v \lambda \dot{\eta}$ quando ele estivesse reunido no ElEcvoíviov e tanto Cefísio quanto Andócides deveriam, também, comparecer.

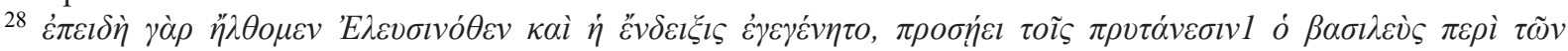


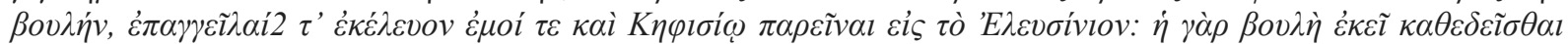

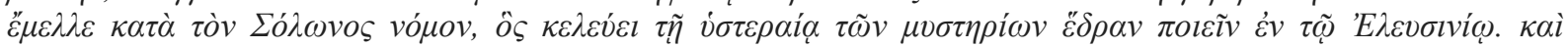

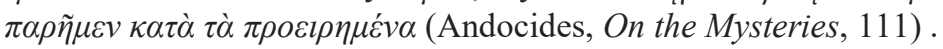


tratados por esses estudiosos como, de algum modo, operando fora da política da polis. ${ }^{29}$ Essencialmente, tratar-se-iam de uma (assim chamada) forma especial de culto, vinculada a um (já brevemente aludido) certo tipo de experiência, a qual não pode ser descrita ou entendida (daí a noção de uma iniciação em um mistério). No entanto, trata-se, ao que tudo indica, de uma concepção baseada em uma ideia moderna de individualismo e numa compreensão completamente atual de religião (ou de seus derivados), entendidos como universais humanos isolados, apolíticos e experienciais - componentes essenciais para que escritores atuais possam afirmar com segurança que "alguma experiência, reconhecidamente, se via presente". ${ }^{30}$ Sem esses componentes, esses estudiosos não seriam capazes de (1) reunir tais instituições, historicamente e socialmente divergentes, e, então, (2) tentar compreendê-las.

Em outras palavras, o que une esses comentaristas contemporâneos é a suposição de que a chave para desvendar o significado e o propósito dos vestígios antigos referentes ao seu objeto de estudo está em nosso senso moderno de indivíduo como um meio isolado e experiencial que existe desassociado e, portanto, potencialmente alheio, do conjunto de instituições que chamamos de Estado. ${ }^{31}$ Essa noção de uma "experiência profundamente sentida" paira sobre os mistérios não apenas como uma explicação, mas como uma suposição subjacente que permite aos classicistas escrever acerca de algo que (conforme o amplamente reconhecido) sabemos muito pouco - ou talvez nada. De acordo o apontado pela historiadora Joan Wallach Scott, quando estudiosos do passado referenciam as experiências como fontes casuais de ação, essas assumem funções estratégicas para tais escritores, uma vez que:

\section{[elas] operam dentro de uma construção ideológica que não apenas torna o indivíduo [destacado de seu contexto] o ponto de partida do conhecimento, mas também naturaliza uma diversidade de categorias (tais como homem, mulher, negro, branco, heterossexual e homossexual) ao trata-las [igualmente, destacadas de seu contexto] como traços característicos dos agentes passados. ${ }^{32}$}

No caso em questão, o que acaba sendo naturalizado - ou seja, anacronicamente retratado como universal e a-histórico - é o "self religioso" isolado e apolítico, possuidor de uma relação pessoal e íntima com o (suposto) "sagrado", que, por sua vez, seria, obviamente, independente e, portanto, existiria antes e fora das instituições sociais (algo evidente em leituras que tratam ambientes tais como os cultos dos mistérios como o espaço onde uma presumida "experiência do sagrado" poderia ser sentida).

\footnotetext{
${ }^{29}$ Cf. BURKERT, Ancient Mystery Cults, p. 10.

${ }^{30}$ Ibidem, p. 114; Cf. GREEN, From Alexander to Actium.

${ }^{31}$ Cf. COSMOPOULOS, Greek Mysteries, p. XII; BOWDEN, Mystery Cults of the Ancient World, p. 6-8; 48-67.

${ }^{32}$ SCOTT, Joan Wallace. The evidence of experience. Critical Inquiry, v. 17, n. 4, 1991, p. 782.
} 
Em síntese, o que esse tipo de abordagem propõe é a existência de uma experiência indescritível, porém transcendental, que seria compartilhada por todos os participantes desses cultos. ${ }^{33}$ Alguns estudiosos então têm se utilizado de tal interpelação na tentativa de explicar os mistérios, o que resulta em um certo tipo de classificação que tenta identificar sua condição sine qua non, ou seja, uma maneira de categorizá-los e compreendê-los sem a qual esses chamados "cultos de mistério" não poderiam ser entendidos como independentes de outras realidades sociais de seu tempo e, portanto, sem a qual não poderiam ser interpretados como expressões de um certo tipo de religiosidade universal (de uma sacralidade perene sui generis). Dessa forma, formata-se todo um programa de pesquisa concebido de forma alheia à noção de que (conforme o anteriormente sugerido) categorias como "experiência"34 e "religiosidade pessoal" não são emblemas históricos de debates passados, mas anacronismos utilizados por estudiosos modernos na naturalização de elementos-chave de seu próprio mundo social.

\section{Acerca da distinção e da classificação}

Com tal contexto em mente, um dos traços mais interessante acerca do estudo desses chamados "cultos de mistério" são os próprios termos utilizados pelos classicistas na tentativa de distingui-los daquilo que concebem como a "religião oficial" ou do Estado e que, portanto, formatam o dispositivo que permite que alguns hoje falem sobre tais instituições como constituindo um fenômeno distinto de outras esferas culturais - uma abordagem que (de acordo com o já mencionado) quando examinada com mais cautela, se mostra problemática, na medida em que se pode argumentar que tais instituições não eram tão distintas ou separadas assim dos demais componentes da vida social antiga. ${ }^{35}$

Por certo, se um determinado fenômeno antigo pode ser entendido como uma criação das atuais sensibilidades e suposições acadêmicas, então pode-se supor que autores modernos diferentes, com idiossincrasias e interesses distintos, possam interpretar os vestígios antigos de maneira ligeiramente divergente (pelo menos pontualmente), decidindo por selecionar observações distintas na constituição de seus agrupamentos conceituais. Tal característica -

\footnotetext{
${ }^{33}$ Cf. NILSSON, Greek Folk Religion, p. 64; BOWDEN, Mystery Cults of the Ancient World, p. 221.

${ }^{34} \mathrm{O}$ cientista da religião Robert Sharf caracterizou essa noção indefinida de "experiência" como um significante vazio que parece permitir, aos autores que o utilizam, concluir que se refere a algo uniformemente presente ao longo do tempo (SHARF, Experience, p. 94-116).

${ }^{35}$ Cf. PARKER, Robert. On Greek Religion. Ithaca e Londres: Cornell University Press, 2011.
} 
fruto cada vez mais decorrente do, supracitado, esforço contemporâneo em tentar identificar e nomear os (chamados) "cultos de mistérios" como um aspecto distinto da vivência antiga talvez seja bem ilustrada pela dificuldade atual em se alcançar uma descrição e configuração precisa para aqueles grupos antigos que os estudiosos contemporâneos (conforme o anteriormente exposto) frequentemente caracterizam como compondo "associações". ${ }^{36}$ Pois, sob tal amplo termo, da mesma forma como podemos observar em sistemas de classificação científica, podem ser alocadas várias subdivisões, como é o caso dos "cultos de mistério". 37

Consequentemente, poderia tal problema estar relacionado com uma suposta inconsistência ou ambiguidade do passado ou a realidade é a de que nossos interesses, termos e esforços modernos para nomear e ordenar esse passado (e, dessa forma, dar sentido a ele) estão fadados ao fracasso quando assumimos que, de alguma forma, eles se referem unicamente ao tempo o qual estudamos, podendo, dessa forma descreve-lo com precisão? A dificuldade em traçarmos configurações e descrições precisas reside no material com o qual trabalhamos ou nas inconsistências dos interesses modernos e em como manipulamos esses materiais? Além da noção de "associação de culto", como encarar os outros descritores que podem, muito bem, vir a ser invenções modernas que anacronicamente projetamos sobre o passado, como se estivessem sempre presentes nos dados, conforme é o caso da distinção entre privado e público, a ideia de uma "escolha voluntária" (que acaba por pressupor um modelo específico de agência individual), ou, em si, a própria noção de “culto religioso"? Em concordância com o já sugerido inúmeras vezes, aquilo que (aqui) devemos nos atentar são as maneiras possíveis por meio das quais os estudiosos que realizam tais distinções, a fím de dar sentido ao passado, estariam, na realidade, sendo os criadores daqueles fenômenos os quais pensam estar meramente descobrindo e descrevendo. ${ }^{38}$

Nesse contexto, recordemo-nos que muitos acadêmcios atuais concordariam que o próprio termo "religião" (denotando um sistema de crença ou fé, expresso secundariamente em forma de ação ritual e que, de algum modo, é distinguível de todos os outros aspectos da vida social) é, em si, uma invenção moderna. Esses autores, portanto, insistiriam que o

\footnotetext{
${ }^{36} \mathrm{O}$ exemplo do conceito de "associação" é, aqui, utilizado como compondo apenas mais um programa de pesquisa o qual, segundo a tese central do presente artigo, deveria ser repensado - um programa que, muito provavelmente, deveria observar com maior atenção a possibilidade de suas próprias classificações estarem criando o fenômeno o qual objsetiva.

${ }^{37}$ KLOPPENBORG, John S. (Org.). Voluntary Associations in the Greco-Roman World. Londres e Nova York: Routledge, 1996, p. 19.

${ }^{38}$ Cf. CHANIOTIS, Angelos. Religious organizations and bodies: Greece. In: JOHNSTON, S. L. (Org.). Religions of the Ancient World: A Guide. Cambridge: Harvard University Press, 2004, p. 319.
} 
conceito de "religião", se aplicado no que refere ao estudo mundo grego antigo, deveria ser usado de maneira cautelosa e qualificada. Em outras palavras, o ponto de tal crítica não é se os indivíduos passados possuiam ou não estados cognitivos que lhes permitiam acreditar que entidades poderosos e invisíveis poderiam existir ou viviam no topo do Monte Olimpo (esse, muito provavelmente, era o caso) ${ }^{39}$; em vez disso, o que se argumenta é que a noção de "religião" como algo distinguível não possui aplicabilidade fora do contexto da modernidade européia.

Com tal compreensão em mente - de um mundo antigo isento de uma esfera distinta que pudesse ser separada e denominada "religiosa" (ou, até mesmo, de "religião") - o caso dos cultos de mistério, religiões de mistério ou associações religiosas ganha um interesse particular para qualquer estudioso preocupado com as consequências das classificações acadêmicas. De fato, os vários nomes utilizados em sua descrição não são indicativos de uma ambiguidade nos dados antigos, mas do dissenso ${ }^{40}$ entre os estudiosos modernos quanto à definição do objeto ao qual se referem. Pois "cultos de mistério" é um termo que não tem suas origens da Antiguidade, mas no pensamento clássico do século XIX, que estava principalmente interessado em exibir "nossa superioridade sobre eles", no caso, colocar a igreja cristã acima e contra os, então chamados, "cultos misteriosos bárbaros ou pagãos". 41 Mais tarde, durante o século XX, de acordo com a mudança do interesse acadêmico, previsivelmente encontramos outros termos sendo desenvolvidos, tais como "associações voluntárias", na tentativa de se realizar um tipo de empreitada bastante diferente daquela estabelecida pelas gerações anteriores. Pois, uma vez que os estudiosos começaram a utilizar o classificador "associação voluntária" para designar tanto os chamados "cultos de mistério" quanto o próprio cristianismo primitivo, isso permitiu que eles delineassem novos limites de

\footnotetext{
${ }^{39}$ Ao passo que cientistas cognitivos parecem concordar que muitas das capacidades especificamente humanas (tais quais a sociabilidade e a competência linguística) são produtos adaptativos de nossa história evolutiva, a maioria considera que o fenômeno religioso seja, assim como muitas outras práticas culturais, um subproduto evolutivo de nossa espécie. Ou seja, enquanto as religiões não seriam, em si, uma adaptação evolutiva, tratar-seiam de construções sociais sobre propensões cognitivas que, por sua vez, o são (SILVA, Thales M., M., SANTOS, Lucas S. Ciências cognitivas, história e o estudo comparativo das religiões: pela definição de um conceito formal e historicamente tangível de "religião". Sacrilegens, v. 14, n. 2, 2017, p. 27). Em outras palavras (e indo de acordo com o argumento central do presente artigo) aquilo que tratamos como "religião" não seria um tipo natural (uma família de entidades possuidoras de propriedades sujeitadas a leis naturais), nem mesmo uma estrutura histórica estável, sobre a qual a seleção natural poderia agir (Cf. KUNDT, R. Contemporary Evolutionary Theories of Culture and the Study of Religion. Londres: Bloomsbury Academic, 2017).

${ }^{40}$ Conforme o argumento central do presente artigo, um dissenso que emerge da insistência, por parte de certos autores, em tentar isolar e identificar como sui generis e privado "um fenômeno" (enfaticamente tratado em sua singularidade) que, ao que tudo indica, originalmente, possuía um caráter fundamentalmente público e múltiplo.

${ }^{41}$ Cf. SMITH, G., C., M. On the significance of some echoed phrases in Euripides' Hippolytus. The Classical Review, v.4, n.4, 1990, p. 149-150.
} 
análise, constituindo, assim, novos fenômenos a serem estudados. Possibilitava-se, então, que o estudo do cristianismo primitivo fosse realizado em conjunto com outros tipos de associações voluntárias (o que se objetivava, dessa forma, era minar as afirmações de uma suposta singularidade cristã, frequentemente encontradas nos demais trabalhos acerca de seus primórdios). O esforço de toda uma geração de classicistas passava, dessa forma, a ser o de entender as origens cristãs não como um Big Bang miraculoso (conforme era o entendimento teológico da época) mas como um evento histórico interno a um contexto social mais amplo. Conscientemente, estudiosos compartilhando tal interpretação alternativa procuraram análogos antigos para seu objeto de estudo, encontrando-nos naquilo que identificaram como “associações voluntárias". ${ }^{2}$

Por conseguinte, nos é de grande interesse considerar, por exemplo, a maneira como,

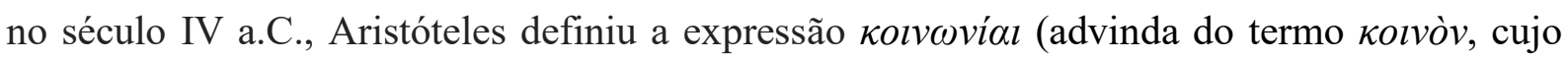
significado aproximado é "comum", “compartilhado"), uma palavra que, atualmente, é frequentemente traduzida como "associações" ou "sociedades" - partindo do pressuposto de que eram, integralmente, grupos privados, separados da religião oficial pública. Entretanto, a definição fornecida pelo filósofo grego não parece (de forma alguma) corresponder às necessidades estabelecidas pelos estudiosos modernos; pois, conforme o elaborado em sua obra, Ética a Nicômaco:

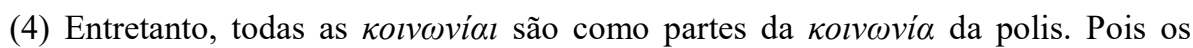
homens se unem (ou coexistem) em busca de alguma vantagem e como forma de assegurar algumas das necessidades da vida. E, da mesma maneira, a kolvwvía da polis, ao que parece, foi originalmente constituída e continua a perdurar em prol da vantagem de seus membros. De fato, esse é o objetivo dos legisladores, os quais dizem que a justiça é o bem comum. (5) As outras kolvwvíal, todavia, visam alguma parte desse bem comum: por exemplo, os marinheiros se organizam como forma de buscar os lucros da guerra, sejam esses o dinheiro, a vitória ou a captura de uma

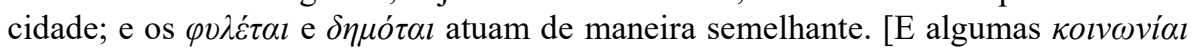

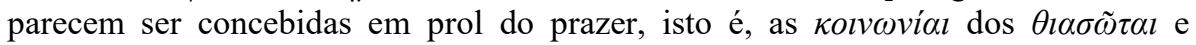

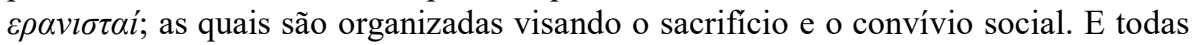

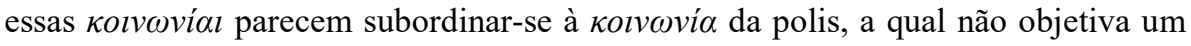
ganho presente, mas visa aquilo que é rentável por toda a vida]. $\mathrm{E}$ as pessoas oferecem sacrifícios e organizam encontros para prestar honra aos deuses e proporcionar descanso e prazer a si mesmas. Pois pode-se notar que os sacrifícios e festivais de origens antigas ocorrem após a colheita, constituindo, de fato, festivais da primeira safra ${ }^{43}$; e isso porque essa era a estação do ano na qual as pessoas dispunham de um maior lazer. (6) Portanto, todas essas kolvwvíal aparentam ser

\footnotetext{
${ }^{42}$ Cf. HARLAND, Philip A. Associations, Synagogues and Congregations. Minneapolis: Fortress Press, 2003; Dynamics of Identity in the World of Early Christians. Londres e Nova York: T\&T Clark, 2009.

${ }^{43} \mathrm{~A}$ oferta da $\dot{\alpha} \pi \alpha \rho \chi \grave{\eta}$ (a primeira porção de uma colheita) também era realizada em honra à deidade eleusina. Para uma descrição detalhada e um extenso comentário a respeito do "decreto da Primeira Safra" (também conhecido como "decreto do Primeiro Fruto"), o texto responsável pela regulamentação de tal prática em Elêusis, Cf. CAVANOUGH, Maureen B. Eleusis and Athens: Documents in Finance, Religion and Politics in the Fifth Century B.C. Atlanta: The American Philological Association, 1996.
} 
partes da polis e as relações as quais discutimos estão em concordância com essas

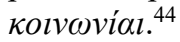

É importante observar que essa definição diz respeito a uma ordem hierárquica que

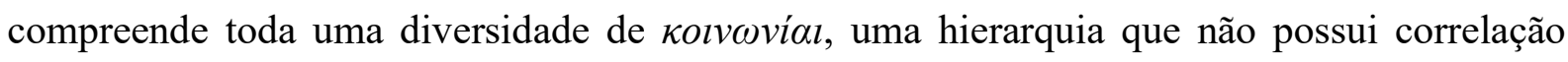
alguma com os interesses acadêmicos modernos em questões relativas ao "privado versus público", "religioso versus profano" ou, até mesmo, "voluntário versus obrigatório". $\mathrm{Na}$ realidade, a definição de Aristóteles, ao que tudo indica, se foca primariamente na própria polis como a kolvwvía definitiva, a qual se concentra naquilo que o filósofo grego retrata

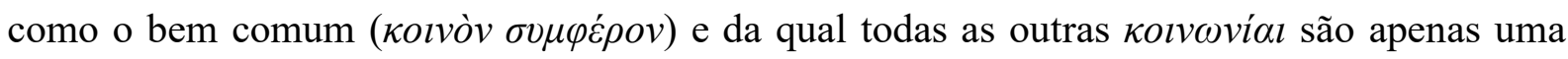
parte, cada uma delas, também, visando, em termos gerais, seu próprio bem comum. Logo,

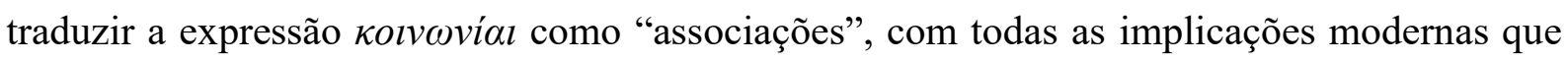
tal termo possui é, de certa forma, uma falha de descrição (pois - conforme o observado - é possível oferecer uma leitura distinta e não menos plausível do texto de Aristóteles, a qual, por sua vez, poderia reivindicar o status de uma mera descrição das declarações realizadas pelo filósofo grego) que, não obstante, opera de maneira eficaz na "constituição de um tipo particular de passado antigo, concebido de acordo com nossa própria imagem moderna". ${ }^{45}$

Logo, a dificuldade em se chegar a uma taxonomia clara, consistente e correta e, portanto, uma definição adequada para identificar os cultos de mistério como algo distintamente separado das outras dimensões da vida cotidiana antiga, não está no "atordoante conjunto de termos gregos e latinos" existentes para sua descrição. ${ }^{46}$ Também não pode ser encontrada na (suposta) "inconsistência” por parte dos autores clássicos e em como eles aplicavam seus próprios termos - pois, obviamente, esses indivíduos e seu público alvo não tinham nenhuma dificuldade atípica em entender seu próprio vocabulário e utilizá-lo, de forma rica e engenhosa, na descrição e compreensão de seu mundo. Evidentemente, não

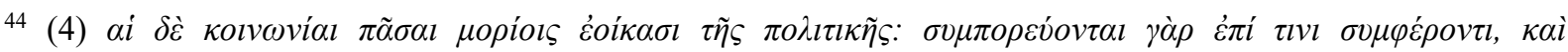

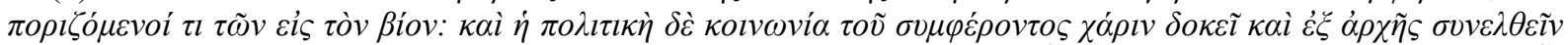

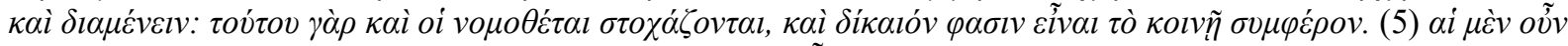

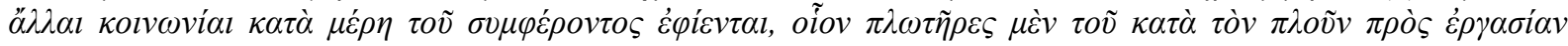

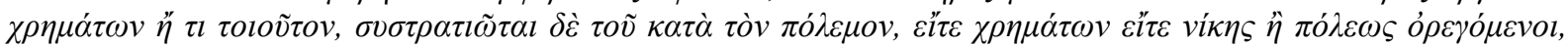

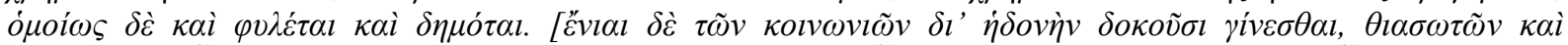

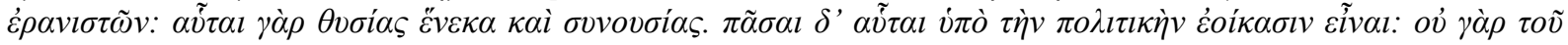

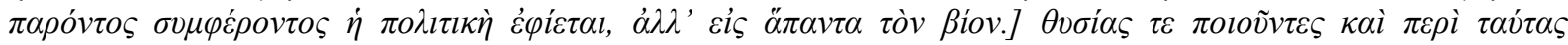

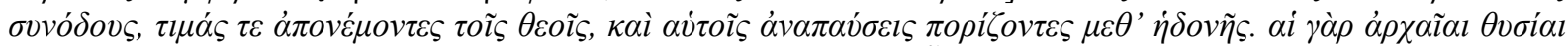

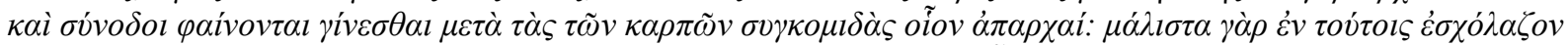

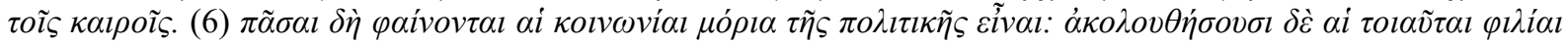

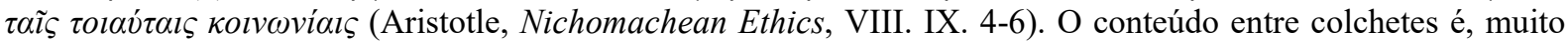
provavelmente, um fragmento interpolado de uma versão paralela do texto.

45 JONES, Nicholas F. The Associations of Classical Athens: The Response to Democracy. Oxford: Oxford University Press, 1999, p. 27-33.

${ }^{46} \mathrm{Cf}$. KLOPPENBORG, Voluntary Associations in the Greco-Roman World.
} 
podemos excluir a possibilidade de que o significado dos termos usados por esses autores antigos fosse, também, alvo de debates e questionamentos por suas audiências, mas quando estudiosos modernos parecem estar, inadvertidamente, se inserindo nas questões dos indivíduos que estudam, forma-se um cenário particularmente problemático. Devemo-nos perguntar, portanto, que tipo de interesses os termos, classes e categorias modernas que propõem podem estar promovendo. Consequentemente, a dificuldade em se alcançar uma taxonomia clara, consistente e correta pode ser encontrada na falta de percepção, por parte desses autores, de que nossos conceitos atuais (nossas categorias taxonômicas) não necessariamente refletem ou descrevem a realidade passada de forma precisa, pois nem estão, exatamente, de acordo com as ferramentas conceituais antigas, nem com os antigos interesses sociais que direcionavam seu uso. Ademais (e ressaltando o mencionado anteriormente) parece que, uma vez que essas categorias modernas são colocadas em uso na descrição dos dados passados, elas criam o próprio objeto de estudo que seus usuários acreditam estar, meramente, descrevendo.

\section{Conclusão}

Lembremo-nos que os chamados "cultos de mistério" ou "associações religiosas" são entendidos por grande parte dos classicistas atuais como operando de forma paralela, porém distinta, do que eles chamam de "religião oficial" das cidades-estados - ou seja, aquilo que eles, eventualmente, caracterizam como "associações religiosas privadas" resulta dessa mesma distinção. Ainda (de acordo com tal linha de interpretação), nesses ambientes, seus membros, supostamente, poderiam realizar rituais que seriam de natureza mais arrebatante do que aqueles que os acadêmicos atuais descrevem como compondo a religião oficial pública. ${ }^{47}$ Tal distinção entre público e privado (relacionada a outras distinções frequentes, tais como as entre elite e popular, racional e irracional, além de obrigatório e opcional), decorrente de interesses e abordagens acadêmicas modernas, se fundamenta em uma dicotomia recente uma noção que reforça ainda mais o binarismo contemporâneo entre religião e espiritualidade (ou individualidade) que é tão comumente encontrado, não só no estudo da Antiguidade, mas, também, na maneira como inúmeros atores sociais atuais se identificam, distinguindo-se de seus pares (mas com os quais eles, ainda assim, compartilham uma grande quantidade de

\footnotetext{
${ }^{47}$ HARLAND, Dynamics of Identity in the World of Early Christians, p. 27-28.
} 
similaridades). Por conseguinte, os estudiosos que se valem desses significantes privilegiam, implícita ou explicitamente, um certo tipo de self moderno e, portanto, a noção de uma "expressão mais autêntica e original de religiosidade": a da experiência individual ou pessoal. Esse tipo de religiosidade, juntamente com a ideia de associações voluntárias, por sua vez, justifica a perspectiva contemporânea (que, como mencionado anteriormente, é compartilhada por muitos dos estudiosos das origens cristãs) de que o cristianismo primitivo era um tipo de associação voluntária interna ao Império Romano. Mas como visto, trata-se de uma ideia que é mais semelhante aos entendimentos modernos das práticas cristãs, como sendo apenas uma entre as várias opções do (às vezes conturbado) mercado religioso atual, do que uma mera descrição de seus primórdios antigos.

Assim, o que precisamos compreender é que essas classificações usadas pelos classicistas modernos, como "associações voluntárias", "associações religiosas" e assim por diante, não são possíveis sem, no processo de sua aplicação, seus usuários estabelecerem uma distinção fundamental entre privado e público, voluntário e não-voluntário, religioso e profano (num esforço para criar identidades, traçando limites e estabelecendo fronteiras). Naturalmente, seria sensato supor que os escritores antigos os quais estudamos (e, portanto, os indivíduos do mundo clássico) possuíam suas próprias distinções e classificações, as quais usavam para apoiar seus próprios interesses (e, provavelmente, contestar os dos outros). Mas não podemos perder de vista a lacuna entre seu contexto e o nosso, pois é precisamente isso que, hoje em dia, faz com que seu mundo nos pareça tão confuso e inconsistente; pois seus interesses e as ferramentas utilizadas para realizá-los são estranhos ou, talvez, não tão atraentes aos "paladares modernos", os quais já possuem interesses e ferramentas próprias. ${ }^{48}$

Com categorias tais quais "associações voluntárias", "cultos de mistério" ou "religiões misteriosas", o esforço dos estudiosos das origens cristãs em criar um fenômeno comparativo para estudar os chamados "grupos cristãos primitivos" foi, por um lado, de fato, bemsucedido, ao demonstrar que esses agrupamentos não deveriam ser tratados como uma singularidade, conforme uma longa tradição acadêmica havia sugerido anteriormente; ou seja, que o cristianismo não representou um fenômeno único, sui generis, mas, pelo contrário, que os grupos cristãos primitivos funcionavam apenas como uma alternativa entre tantas outras. ${ }^{49}$

\footnotetext{
${ }^{48}$ BOURDIEU, Pierre. Distinction: A Social Critique of the Judgement of Taste. Cambridge: Harvard University Press, 1984, p. 477.

${ }^{49}$ Notadamente, a respeito do esforço acadêmico de comparar os primeiros cristãos e as religiões da antiguidade tardia, especialmente os chamados "cultos de mistério" e como as suposições teológicas influenciaram tal comparação, Jonathan Z. Smith concluiu que: "raramente os interesses acadêmicos foram cognitivos, pois quase
} 
A ironia está no fato de que aquelas distinções modernas - tais quais as entre privado e público, religioso e profano - que operam no pano de fundo de suas obras acadêmicas e sobre as quais conceitos, talvez bem intencionados, como "associações voluntárias" e "cultos de mistério" se repousam são, em sua grande maioria, operacionalizadas como realidades ontológicas, creditadas como funcionando no passado, basicamente, da mesma maneira como atualmente se dispõem. Conscientemente ou não, ao valerem-se dessas oposições (do "privado versus público", do "religioso versus profano", etc.) os acadêmicos modernos acabam por legitimar e naturalizar o próprio objeto "religião" - apesar da famigerada crítica do uso do termo - no mundo antigo.

É por meio de uma ideia de "experiência transcendental", de algo oculto no interior do espírito humano, que é imutável e que está no cerne dessas categorias, que alguns estudiosos falam de cultos de mistério, associações religiosas, voluntárias ou mesmo de uma determinada linguagem religiosa própria - pois nos acostumamos a tratar, por exemplo, os idiomas nacionais da mesma maneira. ${ }^{50}$ Obviamente, a linguagem está em constante mudança; isto é, sua forma técnica muda, mas, de alguma maneira, muitos estudiosos assumem que suas classificações, seus termos técnicos - embora sejam modernos - ainda seriam capazes de descrever e capturar a essência do original, que é sempre elusiva, mas, segundo creem, eternamente presente (sob a forma das experiências).

\section{Referências bibliográficas}

Andocides, On the Mysteries. In: MAIDMENT, K. J. (Org.). Minor Attic Orators, Volume I: Antiphon, Andocides. Cambridge: Harvard University Press, 1941, p. 325-454.

Apuleius, Metamorphoses (The Golden Ass), Volume II: Books 7-11. Tradução e edição de J. Arthur Hanson. Cambridge: Harvard University Press, 1989.

Aristotle, Nicomachean Ethics. Tradução de H. Rackham. Cambridge: Harvard University Press, 1926.

Asterius Amasenus Episcopus, Encomium in Sanctos Martyres. In: MIGNE, J. -P. (Org.). Patrologiae Cursus Completus, Series Graeca: Patrologiae Graecare Tomus XL. Paris: Imprimerie Catholique, 1863, p. 313-333.

sempre o que se viu foi uma busca apologética" (SMITH, Jonathan Z. Drudgery Divine: On the Comparison of Early Christianities and the Religions of Late Antiquity. Chicago: The University of Chicago Press, 1994, p. 143).

${ }^{50}$ Cf. NILSSON, Greek Folk Religion, p. 64. 
BOURDIEU, Pierre. Distinction: A Social Critique of the Judgement of Taste. Cambridge: Harvard University Press, 1984.

BOWDEN, Hugh. Mystery Cults of the Ancient World. Princeton e Oxford: Princeton University Press, 2010.

BURKERT, Walter. Ancient Mystery Cults. Cambridge e Londres: Harvard University Press, 1987.

CAVANOUGH, Maureen B. Eleusis and Athens: Documents in Finance, Religion and Politics in the Fifth Century B.C. Atlanta: The American Philological Association, 1996.

CHANIOTIS, Angelos. Religious organizations and bodies: Greece. In: JOHNSTON, S. L. (Org.). Religions of the Ancient World: A Guide. Cambridge: Harvard University Press, 2004, p. 319-321.

Clement of Alexandria, The Stromata, or Miscellanies. In: ROBERTS, Alexander, DONALDSON, James (Orgs.). Ante-Nicene Fathers, Volume II: Fathers of the Second Century. Nova York: Charles Scribner's Sons, 1913, p. 299-568.

. Exhortation to the Heathen. In: ROBERTS, Alexander, DONALDSON, James (Orgs.). Ante-Nicene Fathers, Volume II: Fathers of the Second Century. Nova York: Charles Scribner's Sons, 1913, p. 163-207.

CLINTON, Kevin. Stages of initiation in the Eleusinian and Samothracian mysteries. In: COSMOPOUlOS, M. B. (Org.). Greek Mysteries: The Archaeology and Ritual of Ancient Greek Secret Cults. Londres e Nova York: Routledge, 2002, p. 50-78.

COSMOPOUlOS, Michael B. Preface. In: COSMOPOULOS, M. B. (Org.). Greek Mysteries: The Archaeology and Ritual of Ancient Greek Secret Cults. Londres e Nova York: Routledge, 2002.

FITZGERALD, Timothy. Experience. In: BRAUN, W., MCCUTCHEON, R. T. (Orgs.). Guide to the Study of Religion. Londres e Nova York: Cassell, 2000, p. 125-139.

FOLEY, Helene P. (Org.).The Homeric Hymn to Demeter: Translation, Commentary, and Interpretive Essays. Princeton: Princeton University Press, 1993.

GRAF, Fritz. Lesser mysteries - Not less mysterious. In: COSMOPOULOUS, M. B. (Org.). Greek Mysteries: The Archaeology and Ritual of Ancient Greek Secret Cults. Londres e Nova York: Routledge, 2002, p. 241-262.

GREEN, Peter. From Alexander to Actium: The Hellenistic Age. Londres: Thames and Hudson, 1990.

HARLAND, Philip A. Associations, Synagogues and Congregations. Minneapolis: Fortress Press, 2003. 
Clark, 2009.

Dynamics of Identity in the World of Early Christians. Londres e Nova York: T\&T

Hippolytus, Refutation of All Heresies. In: ROBERTS, Alexander, DONALDSON, James (Orgs.). Ante-Nicene Fathers, Volume V: Fathers of the Third Century. Nova York: Charles Scribner's Sons, 1919, p. 9-163.

JONES, Nicholas F. The Associations of Classical Athens: The Response to Democracy. Oxford: Oxford University Press, 1999.

KLOPPENBORG, John S. (Org.). Voluntary Associations in the Greco-Roman World. Londres e Nova York: Routledge, 1996.

LARSON, Jennifer. Ancient Greek Cults: A Guide. Londres e Nova York: Routledge, 2007.

MARTIN, Craig, MCCUTCHEON, Russell T. (Org.). Religious Experience: A reader. Sheffield: Equinox, 2012.

MARTIN, Luther H. Hellenistic Religions: An Introduction. Nova York e Oxford: Oxford University Press, 1987.

. Studies in Hellenistic Religions. Eugene: Cascade Books, 2018.

KUNDT, R. Contemporary Evolutionary Theories of Culture and the Study of Religion. Londres: Bloomsbury Academic, 2017.

MCCUTCHEON, Russell T. The Discipline of Religion: Structure, Meaning, Rhetoric. Londres: Routledge, 2003.

. Studying Religion: An Introduction. Londres: Equinox, 2007.

NILSSON, Martin. Greek Folk Religion. Nova York: Harper, 1961.

NONGBRI, Brent. Before Religion: A History of a Modern Concept. New Haven e Londres: Yale University Press, 2013.

PARKER, Robert. On Greek Religion. Ithaca e Londres: Cornell University Press, 2011.

Plutarch, Isis and Osiris. In: BABBITT, Frank Cole. Moralia, Volume V. Cambridge: Harvard University Press, 1936, p. 3-194.

ROBERTSON, Noel D. The two processions to Eleusis and the program of the mysteries. The American Journal of Philology, v. 119, n. 4, 1998, p. 547-575.

SCOTT, Joan Wallace. The evidence of experience. Critical Inquiry, v. 17, n. 4, 1991, p. 773797 , 
SHARF, Robert H. Experience. In: TAYLOR, Mark C. (Org.). Critical Terms for Religious Studies. Chicago: University of Chicago Press, 1998, p. 94-116.

SOURVINOU-INWOOD, Cristiane. Festival and mysteries: Aspects of the Eleusinian cult. In: COSMOPOULOS, M. B. (Org.). Greek Mysteries: The Archaeology and Ritual of Ancient Greek Secret Cults. Londres e Nova York: Routledge, 2002, p. 25-49.

SILVA, Thales M., M., SANTOS, Lucas S. Ciências cognitivas, história e o estudo comparativo das religiões: pela definição de um conceito formal e historicamente tangível de "religião". Sacrilegens, v. 14, n. 2, 2017, p. 25-44.

SMITH, G., C., M. On the significance of some echoed phrases in Euripides' Hippolytus. The Classical Review, v.4, n.4, 1990, p. 149-150.

SMITH, Jonathan Z. Imagining Religion: From Babylon to Jonestown. Chicago: University of Chicago Press, 1982.

Drudgery Divine: On the Comparison of Early Christianities and the Religions of Late Antiquity. Chicago: The University of Chicago Press, 1994.

Tertullian, Ad Nationes. In: ROBERTS, Alexander, DONALDSON, James (Orgs.). AnteNicene Fathers, Volume III: Latin Christianity. Nova York: Charles Scribner's Sons, 1918, p. 109-149.

. The Chaplet, or De Corona. In: ROBERTS, Alexander, DONALDSON, James (Orgs.). Ante-Nicene Fathers, Volume III: Latin Christianity. Nova York: Charles Scribner's Sons, 1918, p. 93-105.

The Homeric Hymn to Demeter. In: FOLEY, Helene P. (Org.).The Homeric Hymn to Demeter: Translation, Commentary, and Interpretive Essays. Princeton: Princeton University Press, 1993, p. 2-65.

TOUNA, Vaia. Fabrications of the Greek Past: Religion, Tradition, and the Making of Modern Identities. Leiden e Boston: BRILL, 2017. 